\title{
Socio-Demographic Profile, Burden and Coping in Spouses of Patients with Schizophrenia, Bipolar Disorder and Alcohol Dependence Syndrome- A Cross Sectional Study
}

\author{
Jayamadhuri Mothukuri1 ${ }^{1}$, Ashok Reddy Karredla² \\ ${ }^{1}$ Department of Psychiatry, Shadan Institute of Medial Sciences, Moinabad, Hyderabad, Telangana, India. \\ ${ }^{2}$ Department of Psychiatry, SVS Medial College, Mahabubnagar, Telangana, India.
}

\section{ABSTRACT}

\section{BACKGROUND}

Serious mental illnesses like schizophrenia, bipolar disorder, alcohol dependence syndrome lead to great burden in care givers who adopt a variety of methods to cope with their family member's illness. Burden perceived and coping styles used by spouses is quite different from other care givers given their close relationship with the patient. Little research is focused on spouses as an exclusive group for the assessment of burden \& coping. The aim was to study the socio-demographic profile, the burden and coping in the spouses of patients with schizophrenia, bipolar disorder and alcohol dependence syndrome.

\section{METHODS}

This study was conducted at the Institute of Mental Health, Hyderabad, among 180 study participants including spouses (30 male \& 30 female) from patient groups of the above three illnesses. After obtaining written informed consent, patient and spouse were interviewed with a semi-structured intake pro-forma to capture the socio-demographic details of spouse, illness, marital, family \& treatment history. After initial assessment of patient's functional status using GAF scale; BAS, CCL, GHQ-12 instruments were administered on spouses to assess the burden of illness, coping styles and general health status. SPSS 17 was applied to the data.

\section{RESULTS}

Alcohol use and mental illness is high in families of patients with alcohol dependence reaching statistical significance. Nuclear families are high in schizophrenia group and in alcohol dependence group, substance use in spouses is high at $25(52.1 \%)$ along with abuse of spouses at $19(67.9 \%)$ with statistical significance. Also, means of GHQ-12 in alcohol dependence group is higher than other groups while means of BAS is higher in alcohol dependence group.

\section{CONCLUSIONS}

Burden perceived by spouses of these three patient groups is significant. The coping styles used by spouses to handle the distress due to patient's illness are many. A high global functioning score of the patient corresponds to good general health in the spouse. Proper psychosocial interventions when employed can help spouses deal better with burden and enhance coping styles.

\section{KEY WORDS}

Spouses, Burden, Coping, General Health, Schizophrenia, Bipolar Disorder, Alcohol Dependence Syndrome

\author{
Corresponding Author: \\ Dr. Jayamadhuri Mothukuri, \\ H. No. 11-24-108, Shathavahanapuri, \\ Desaipet Road, Warangal-506002, \\ Telangana, India. \\ E-mail:jmothukure@gmail.com
}

DOI: 10.14260/jemds/2020/259

Financial or Other Competing Interests: None.

How to Cite This Article:

Mothukuri J, Karredla AR. Sociodemographic profile, burden and coping in spouses of patients with schizophrenia, bipolar disorder and alcohol dependence syndrome- a cross sectional study. J. Evolution Med. Dent. Sci. 2020;9(14): 1192-1197 DOI:
Submission 24-03-2019,

Peer Review 14-03-2020,

Acceptance 21-03-2020,

Published 06-04-2020. 


\section{BACKGROUND}

Individuals with severe mental illness stay ill for long durations, unable to fulfil normal roles expected for their age and intellectual ability by society. Most persons with Schizophrenia are now having community care by families impacting caregivers due to the advent of deinstitutionalization. ${ }^{1}$ The evaluation of caregiver's impact of mental illness is in the form of burden, psychological morbidity, coping, finance. Burden of care is defined as "the presence of problems, difficulties or adverse events which affect the life of the psychiatric patients' significant others".

The burden of care concept has two distinct components. ${ }^{2}$

1. Objective burden includes measurable effects in household disruptions, economic burden, loss of work and social activities, time spent negotiating mental health, medical and social welfare and sometimes criminal justice systems.

2. Subjective burden is the caregiver's own perception of the impact of caring consisting of negative feelings of loss, anxiety, anger, sorrow, hatred, uncertainty, guilt, shame or embarrassment, which causes significant distress and suffering.

Subjective psychological distress has been found to be highly prevalent, with 29 to $60 \%$ of the caregivers suffering from diagnosable psychiatric disorders across different studies. ${ }^{3}$ Research evidence from various countries on patients with Schizophrenia caregivers reveal the presence of inadequate help and support plus inability to cope with the caring roles and responsibilities. ${ }^{4}$ Mental illness onset in a family member usually results in whole family's psychological and emotional disturbance. ${ }^{5}$

A study in Malaysia found that a relatives' mental illness compels the caregivers to cope with the stigma impact. ${ }^{6}$ One study highlighted that the family burden and financial burden were significantly higher in persons with Schizophrenia when compared with other mental disorders. ${ }^{7}$ Similarly, two prospective studies conducted in India have found no difference in family burden severity observed between families of patients with Schizophrenia and relatives of Bipolar disorder sufferers. 8,9

Alcohol use has negative effects on the spouse of an alcohol user like feelings of hatred, self-pity, avoidance of social contacts, exhaustion and become physically or mentally ill. Alcohol drinking families were characterized by poorly communicating family members, less mutual warmth and affection, poor role functioning and compatibility between husband and wife leading to unpleasant, tense, cold and inhospitable environment. Greater burden is due to substance dependent person's disrupting activities and financial difficulties arising from income loss and/or funds spent on substance dependence.

Coping strategies of caregivers have been distinguished into two broad groups. Problem-focused strategies refer to constructive coping efforts which modify difficult situations such as problem solving, seeking information, or using positive methods of communication. Emotion-focused strategies like avoiding or resigning themselves to the situation are less adaptive attempts at modulating the caregiver's stress-related emotional response. Caregiverburden, patient's social functioning, and expressed emotions of caregivers and social support available are the most consistent correlates of coping. High levels of burden, dysfunction, and expressed emotions together with low levels of available support are associated with maladaptive emotion-focused styles such as avoidance, resignation, coercion, etc.

Problem focused coping strategies were more frequent among young relatives and relatives of younger patients. Relatives who lived longer with the patient and having poor social support frequently adapted emotion-focused strategies. ${ }^{10}$ The coping behaviour of wives of persons with alcohol dependent are emotional, tolerant, inactive, controlling, confronting and supporting the user.11 The perception of needs study of the patients of Schizophrenia by themselves and their family members revealed that the number of needs as perceived by the caregivers \& patients was similar. Most of the needs are met in the West, however in India more than two third needs of Schizophrenia patients were unmet, especially welfare benefits. ${ }^{12}$

When an experience of illness onset in spouses of schizophrenic patients was investigated, the finding was first episode of a schizophrenic disorder leads to severe distress in the spouse of the patient that is often viewed as an existential threat to marriage and family life. If spouses feel that neither their information about the disease nor their supportive resources are sufficient, emotions of fear, despair and loss of control are especially pronounced. Supportive services for these spouses should be offered very closely to the onset of Schizophrenia, as it is very burdensome in this period. Interventions should meet the particular needs of spouses giving information about the illness and coping strategies plus considering issues relevant for partnership and parenting roles. ${ }^{13,14}$

Burden and coping in caregiver parents and spouses of patients of Schizophrenia when studied, greater emotional burden found in spouses and denial was most used coping strategy by parents, with negative distraction strategies used more b spouses. Patient's age, educational level, and level of functioning and caregiver's use of denial as a coping strategy emerged as significant predictors of caregiver burden on stepwise regression analysis. ${ }^{15,16}$ A review of burden of Schizophrenia in caregivers examining the role of gender reveals that relatives of male patients frequently experience more social dysfunction and disabilities than those of female patients. An extensive literature also demonstrated the positive impact of various family interventions in improving family environment, reducing relapse and easing the burden of care. Access to better treatment for patients, including medications, psychosocial interventions and rehabilitation services, are important basic elements in easing the burden on caregivers. ${ }^{17}$

In a review of the factors that influence experienced burden, coping and needs for support of caregivers for patients with a Bipolar disorder, both objective and subjective burden is high and subjective burden being extremely influenced by illness beliefs. High burden is associated more with severity of symptoms, difficulties in the relationship with patient, lack of support and stigma. Coping is influenced by appraisal and burden with different phases in care giving requiring different coping mechanisms. It's recommended to increase support for these caregivers. ${ }^{18,19} \mathrm{~A}$ study of family burden among relatives of patients with 


\begin{tabular}{|c|c|c|c|c|c|c|}
\hline $\begin{array}{l}\frac{0}{0} \\
\frac{\pi}{\pi} \\
\frac{\pi}{\nu}\end{array}$ & 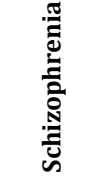 & 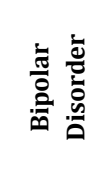 & 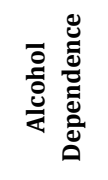 & : & 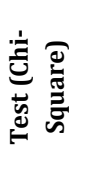 & is \\
\hline \multicolumn{7}{|c|}{ Education of spouse } \\
\hline Nil & $28(46.7)$ & $14(23.3)$ & $18(30)$ & 60 & \multirow{5}{*}{12.42} & \multirow{5}{*}{13} \\
\hline Primary & $19(30.6)$ & $22(35.5)$ & $21(33.9)$ & 62 & & \\
\hline SSC & $10(25.6)$ & $13(33.3)$ & $16(41)$ & 39 & & \\
\hline Intermediate & $2(18.2)$ & $6(54.5)$ & $3(27.3)$ & 11 & & \\
\hline Degree & $1(12.5)$ & $5(62.5)$ & $2(25)$ & 8 & & \\
\hline \multicolumn{7}{|c|}{ Employment of spouse } \\
\hline Unemployed & 0 & 0 & $1(100)$ & 1 & \multirow{6}{*}{12.5} & \multirow{6}{*}{.253} \\
\hline Homemaker & $12(31.6)$ & $13(34.2)$ & $13(34.2)$ & 38 & & \\
\hline Farmer & $9(24.7)$ & $15(42.9)$ & $11(31.4)$ & 35 & & \\
\hline Labourer & $20(34)$ & $16(27)$ & $23(39)$ & 59 & & \\
\hline Job & $11(32.4)$ & $11(32.4)$ & $12(35.5)$ & 34 & & \\
\hline Others & $8(61.5)$ & $5(38.5)$ & 0 & 13 & & \\
\hline \multicolumn{7}{|c|}{ Type of family } \\
\hline Joint & $28(26.2)$ & $39(36.4)$ & $40(37.4)$ & 107 & \multirow{2}{*}{6.13} & \multirow{2}{*}{$.04^{*}$} \\
\hline Nuclear & $32(43.8)$ & $21(28.8)$ & $20(27.4)$ & 73 & & \\
\hline \multicolumn{7}{|c|}{ Financial dependence on patient } \\
\hline Yes & $26(36.6)$ & $19(26.8)$ & $26(36.6)$ & 71 & \multirow{2}{*}{2.279} & \multirow{2}{*}{.32} \\
\hline No & $34(31.2)$ & $41(37.6)$ & $34(31.2)$ & 109 & & \\
\hline \multicolumn{7}{|c|}{ Mental illness in spouse } \\
\hline Yes & $9(37.5)$ & $11(45.8)$ & $4(16.7)$ & 24 & \multirow{2}{*}{3.75} & \multirow{2}{*}{.15} \\
\hline No & $51(32.7)$ & $49(31.4)$ & $56(35.9)$ & 156 & & \\
\hline \multicolumn{7}{|c|}{ H/o substance abuse in spouse } \\
\hline Yes & $10(20.8)$ & $13(27.1)$ & $25(52.1)$ & 48 & \multirow{2}{*}{10.73} & \multirow{2}{*}{$0.005^{*}$} \\
\hline No & $50(37.9)$ & $47(35.6)$ & $35(26.5)$ & 132 & & \\
\hline \multicolumn{7}{|c|}{ H/o of abuse in spouse } \\
\hline Yes & $3(10.7)$ & $6(21.4)$ & $19(67.9)$ & 28 & \multirow{2}{*}{18.35} & \multirow{2}{*}{$.00^{*}$} \\
\hline No & $57(37.5)$ & $54(35.5)$ & $41(27)$ & 152 & & \\
\hline & & $\begin{array}{r}a c i o-D e \\
\text { acros }\end{array}$ & $\begin{array}{l}\text { aphic Pro } \\
\text { hree Grov }\end{array}$ & & & \\
\hline
\end{tabular}

\begin{tabular}{|c|c|c|c|c|c|}
\hline Variable & $\begin{array}{c}\text { Schizophrenia } \\
\text { Mean (SD) }\end{array}$ & $\begin{array}{c}\text { Bipolar } \\
\text { Disorder } \\
\text { Mean (SD) }\end{array}$ & $\begin{array}{c}\text { Alcohol } \\
\text { Dependence } \\
\text { Mean (SD) }\end{array}$ & $\begin{array}{c}\text { One-Way } \\
\text { ANOVA } \\
\text { F-Value }\end{array}$ & p \\
\hline GHQ-12 & $18(1.95)$ & $18.58(2.51)$ & $19.43(3.36)$ & 4.354 & $.014^{*}$ \\
\hline \multicolumn{2}{|c|}{ Table 3. Mean Scores of GHQ-12 across the Three Groups } \\
\hline
\end{tabular}

\begin{tabular}{|c|c|c|c|c|c|}
\hline Variable & $\begin{array}{c}\text { Schizophrenia } \\
\text { Mean (SD) }\end{array}$ & $\begin{array}{c}\text { Bipolar } \\
\text { Disorder } \\
\text { Mean (SD) }\end{array}$ & $\begin{array}{c}\text { Alcohol } \\
\text { Dependence } \\
\text { Mean (SD) }\end{array}$ & $\begin{array}{c}\text { One-Way } \\
\text { ANOVA } \\
\text { F-Value }\end{array}$ & p \\
\hline BAS & $79.68(5.41)$ & $81.4(4.41)$ & $83.6(6.95)$ & 7.261 & $.001^{*}$ \\
\hline \multicolumn{6}{|c|}{ Table 4. Mean Scores of Burden Assessment Schedule } \\
across the Three Groups
\end{tabular}

\begin{tabular}{|c|c|c|c|c|c|}
\hline Variable & $\begin{array}{c}\text { Schizophrenia } \\
\text { Mean (SD) }\end{array}$ & $\begin{array}{c}\text { Bipolar } \\
\text { Disorder } \\
\text { Mean (SD) }\end{array}$ & $\begin{array}{c}\text { Alcohol } \\
\text { Dependence } \\
\text { Mean (SD) }\end{array}$ & $\begin{array}{c}\text { One-Way } \\
\text { ANOVA } \\
\text { F-Value }\end{array}$ & $\mathbf{p}$ \\
\hline $\begin{array}{c}\text { CCL-problem } \\
\text { focused }\end{array}$ & $1.41(.61)$ & $1.4(.64)$ & $1.38(.62)$ & .294 & .764 \\
\hline $\begin{array}{c}\text { CCL-positive } \\
\text { distraction }\end{array}$ & $1.01(.59)$ & $.95(.62)$ & $.833(.64)$ & 1.34 & .264 \\
\hline CCL-acceptance & $1.85(.77)$ & $1.88(.76)$ & $1.78(.73)$ & .27 & .764 \\
\hline CCL-religion & $2.20(.97)$ & $2.35(.89)$ & $2.11(1.07)$ & .866 & .422 \\
\hline CCL-denial & $1.0(.58)$ & $.967(.609)$ & $1.05(.565)$ & .307 & .736 \\
\hline $\begin{array}{c}\text { CCL-social } \\
\text { support }\end{array}$ & $1.88(.99)$ & $1.55(.99)$ & $1.66(.96)$ & .176 & .175 \\
\hline \multicolumn{7}{|c|}{ Table 5. Coping Styles across the Groups Using Coping Check List } \\
\hline
\end{tabular}

\begin{tabular}{|c|c|c|c|c|c|}
\hline Variable & $\begin{array}{c}\text { Schizophrenia } \\
\text { Mean (SD) }\end{array}$ & $\begin{array}{c}\text { Bipolar } \\
\text { Disorder } \\
\text { Mean (SD) }\end{array}$ & $\begin{array}{c}\text { Alcohol } \\
\text { Dependence } \\
\text { Mean (SD) }\end{array}$ & $\begin{array}{c}\text { One-Way } \\
\text { ANOVA } \\
\text { F-Value }\end{array}$ & $\mathbf{p}$ \\
\hline GAF & $64.08(61.5)$ & $59.88(10.01)$ & $55.28(12.3)$ & .862 & .424 \\
\hline \multicolumn{4}{|c|}{ Table 6. Global Assessment of Functioning in } \\
Patients across the Three Groups \\
\hline
\end{tabular}

\section{DISCUSSION}

Although available literature studied burden of care and coping styles in caregivers broadly, studies on spouses are less in whom the impact and perception of illness is different to other care givers in family. The present study aims to assess the socio-demographic profile, burden and coping exclusively in spouses of patients with Schizophrenia, Bipolar disorder and alcohol dependence syndrome. The significant findings are discussed.

The distribution of religion across the three groups is statistically significant. In alcohol dependence group, love marriages are high along with mental illness. Also, alcohol use is high in families of patients of alcohol dependence. Nuclear families are high in schizophrenia group. In alcohol dependence group, substance use in spouses and spousal abuse is high reaching statistical significance. Mental illness in families of spouse is found to be high in alcohol dependence group along with alcohol use reaching statistical significance. Prior studies found no difference in burden between alcohol dependence group and BPAD group. In contrast, this study reveals that means of burden in alcohol dependence are higher than other two groups reaching statistical significance.

A study revealed that emotion-focused coping strategy is found in most of the Schizophrenic relatives. ${ }^{29}$ Fatalism and problem-solving contributed $26.4 \%$ and $27.4 \%$ of the coping effort of caregivers respectively, followed by passivity, expressive-action and escape-avoidance inference that relatives use a broad range of coping styles. ${ }^{30}$ The present study also points not one but multitude of coping styles being employed by spouses of mentally ill persons. No difference in coping is reported between the caretakers of Schizophrenia and bipolar disorder. ${ }^{9}$ the present study also show no statistical significant difference between coping styles in spouses of patients.

It is found that problem-focused coping strategies were more common in caregivers of Bipolar disorder patients and emotion-focused strategies in caregivers of Schizophrenia patients ${ }^{26}$ whereas in the present study we could not find any statistically significant difference in coping styles. It is found that the common coping style in spouses with mental illness is negative distraction 16 but in the present study no particular coping style is commonly seen in spouses of mentally ill persons.

\section{Limitations}

The current study was conducted at a tertiary care centre that may not represent the general population and study population was mostly from the lower socioeconomic group hence results cannot be projected for middle and higher economic groups. Other factors that influence experience and reporting of burden like social support and expressed emotions were not taken into account.

\section{CONCLUSIONS}

Burden perceived by spouses of schizophrenia, bipolar disorder and alcohol dependence patients is significant and almost similar. Coping styles used by spouses to handle the distress are many. Severity of illness in the patient and general health of the spouse are strongly associated with each other. Measures to improve the treatment effectiveness may lead to reduction of perceived burden in the spouses. Psychotherapeutic techniques like psycho education, family and couple therapy may help in better coping of spouses of 
mentally ill persons. Group therapy can help spouses in sharing their views and understanding of various coping methods employed by others.

In view of perceived burden in the spouses of mentally ill persons, there is a need to develop family intervention programs focusing on psycho education and skill building. Society should ensure access to better rehabilitation and psycho social services. Self-help groups for spouses should be encouraged where they can share \& seek mutual support. Periodic screening of spouses is required given their vulnerability for psychological problems. Financial incentives from the government agencies can help in reducing the burden of spouse.

\section{ACKNOWLEDGEMENT}

Author would like to thank Dr. P.C.B. Gupta, Professor, IMH, Hyderabad for his guidance \& Dr. Ch. Siva Kumar, Associate Professor, Govt. Medical College, Siddipet, Telangana for his constant support.

\section{REFERENCES}

[1] Yip KS. Have psychiatric services in Hong Kong been impacted by the deinstitutionalization and community care movements. Administration and Policy of Mental Health 2000;27(6):443-9.

[2] Hoenig J, Hamilton MW. The schizophrenic patient in the community and his effect on the household. Int J Soc Psychiatry 1966;12(3):165-76.

[3] Avasthi A. Preserve and strengthen family to promote mental health. Indian J Psychiatry 2010;52(2):113-26.

[4] Chan SWC, Yip B, Tso S, et al. Evaluation of a psycho education program for Chinese clients with schizophrenia and their family caregivers. Patient Education and Counselling 2009;75(1):67-76. 2.219.

[5] Chien WT, Chan SWC. One-year follow-up of a multiplefamily-group intervention for Chinese families of patients with schizophrenia. Psychiatric Services 2004;55(11):1276-84.

[6] Chang $\mathrm{KH}$, Horrocks S. Lived experience of family caregivers of mentally ill relatives. Journal of Advanced Nursing 2006;53(4):435-43.

[7] Gururaj GP, Math SB, Reddy JYC, et al. Family burden, quality of life and disability in obsessive compulsive disorder: an Indian perspective. J Postgrad Med 2008;54(2):91-7.

[8] Chadda RK, Singh TB, Ganguly KK. Caregiver burden and coping: a prospective study of relationship between burden and coping in caregivers of patients with schizophrenia and bipolar affective disorder. Social Psychiatry and Psychiatric Epidemiolog 2007;42(11):923-30.

[9] Nehra R, Chakrabarti S, Kulhara P, et al. Caregiver-coping in bipolar disorder and schizophrenia--a re-examination. Social Psychiatry and Psychiatric Epidemiology 2005;40(4):329-36.

[10] Magliano L, Fadden G, Fiorillo A, et al. Family burden and coping strategies in schizophrenia: Are key relatives really different to other relatives? Acta Psychiatr Scand 1999;99(1):10-15.

[11] Orford J, Templeton L, Velleman R, et al. Family members of relatives with alcohol, drug and gambling problems: a set of standardized questionnaires for assessing stress, coping and strain. Addiction 2005;100(11):1611-24.

[12] Kulhara P, Chakrabarti S, Avasthi A, et al. Psychoeducational intervention for caregivers of Indian patients with schizophrenia: a randomised-controlled trial. Acta Psychiatr Scand 2009;119(6):472-83.

[13] Jungbauer J, Angermeyer MC. Living with a schizophrenic patient: a comparative study of burden as it affects parents and spouses. Psychiatry 2002;65(2):110-23.

[14] Jungbauer J, Bischkopf J, Angermeyer MC. The illness has totally changed our lives--stress in partners of schizophrenic patients at the onset of illness. Psychiatr Prax 2001;28(3):133-8.

[15] Rammohan A, Rao K, Subbakrishna DK. Burden and coping in caregivers of persons with schizophrenia. Indian J Psychiatry 2002;44(3):220-7.

[16] Rammohan A, Rao K, Subbakrishna DK. Religious coping and psychological wellbeing in carers of relatives with schizophrenia. Acta Psychiatr Scand 2002;105(5):35662.

[17] Awad AG, Vorungati LNP. The burden of schizophrenia on caregivers: a review. Pharmaeconomics 2008;26(2):149-62.

[18] Van der Voort TY, Goossens PJ, van der Bijl JJ. Alone together: a grounded theory study of experienced burden, coping, and support needs of spouses of persons with a bipolar disorder. Int J Ment Health Nurs 2009;18(6):434-43.

[19] Van der Voort TY, Goossens PJ, van der Bijl JJ. Burden, coping and needs for support of caregivers for patients with a bipolar disorder: a systematic review. Journal of Psychiatric and Mental Health Nursing 2007;14(7):67987.

[20] Maji KR, Sood M, Sagar R, et al. A follow-up study of family burden in patients with bipolar affective disorder. Int J Soc Psychiatry 2012;58(2):217-23.

[21] Perlick DA, Rosenheck RA, Miklowitz DJ, et al. Prevalence and correlates of burden among caregivers of patients with bipolar disorder enrolled in the Systematic Treatment Enhancement Program for Bipolar Disorder. Bipolar Disord 2007;9(3):262-73.

[22] Perlick DA, Rosenheck RA, Clarkin JF, et al. Impact of family burden and affective response on clinical outcome among patients with bipolar disorder. Psychiatr Serv 2004;55(9):1029-35.

[23] Goossens PJ, Van Wijngaarden B, Knoppert EAM, et al. Family care giving in bipolar disorder: caregiver consequences, caregiver coping styles, and caregiver distress. Int J Soc Psychiatry 2008;54(4):303-16.

[24] Mattoo SK, Nebhinani N, Kumar ABN, et al. Family burden with substance dependence: a study from India. Indian J Med Res 2013;137(4):704-11.

[25] Tempier R, Boyer R, Lambert J, et al. Psychological distress among female spouses of male at-risk drinkers. Alcohol 2006;40(1):41-9. 
[26] Chakrabarti S, Gill S, Coping and its correlates among caregivers of patients with bipolar disorder: a preliminary study. Bipolar Disorders 2002;4(1):50-60.

[27] Thara R, Padmavathi R, Kumar S, et al. Burden assessment schedule: instrument to assess burden on caregivers of chronic mentally ill. Indian J Psychiatry 1998;40(1):21-9.

[28] Rao K, Subbakrishna DK, Prabhu GG. Development of coping checklist- a preliminary report. Indian Journal of Psychiatry 1989;31(2):128-33.
[29] Chandrasekaran R, Sivaprakash B, Jayestri SR. Coping strategies of the relatives of Schizophrenia. Indian J Psychiatry 2002;44(1):9-13.

[30] Creado DA, Parkar SR, Kamath RM. A comparison of the level of functioning in chronic schizophrenia with coping and burden in caregivers. Indian J Psychiatry 2006;48(1):27-33. 